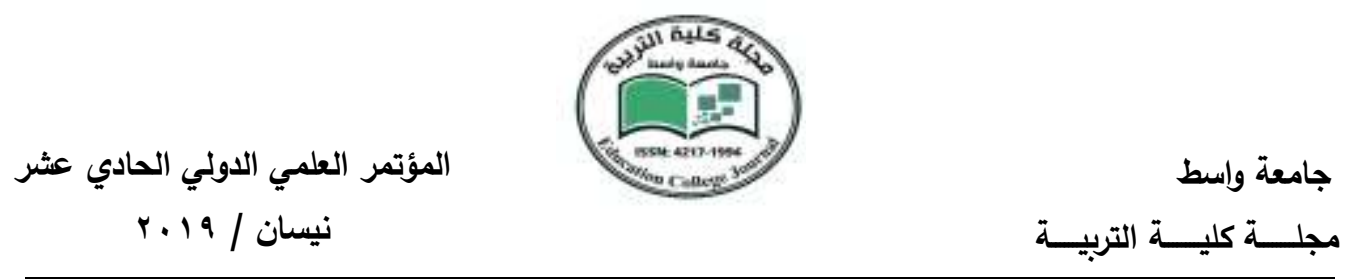

\title{
توظيف التراث في شعر ابن الدمينة
}

\section{كلية الفنون الجميلة / جامع غباشة واسط}

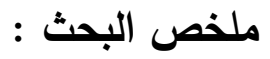

يمثل التراث مخزون الأمة فهو يحافظ على هويتها وانتمائها ،إذ يحوي قيماً ثقافية وفكرية تكون بمرور الزمن جزءاً من تكوين هذه الأمة ، فالتراث مصدر الهام الشعراء فيؤثر فيهم،ويختلف الثعراء في مقدار هذا التأثر كويلجأ الكثير منهم إلى هذا التراث فينهلون منه ويوظفونه في أشعارهم ، والثاعر ابن الدمينة واحد من هؤلاء الشعراء وهو شاعر إسلامي من شعراء الغزل العذري استطاع توظيف التراث العربي في شعره .فكان عنوان البحث (توظيف التراث في شعر ابن الدمينة). وقسم البحث إلى مدخل تحدثت فيه عن حياة الثاعر وعصره وشعره ، وتتاول المبحث الأول التراث الديني، أما المبحث الثاني فكان خاصاً بالتراث الأدبي والأمثال، أما المبحث الثالث فكان للحديث عن التراث التاريخي، ثم خاتمة البحث ونتائجه ،وقائمة بالمصادر والمراجع •

\section{Research Summary:}

Heritage represeent s stok It preserres its identity and belonging heritage is the source of inspiration poets affect them, and many of them rcsort to this heritage vnhlon it and employ it their poetry, and the poet Ibn al-Damianah one of these poets, an Islamic poet of the poets spinning virgin could employ the Arab heritage in his poetry . The title of the research(The exploitation of heritage in the poetry of Ibn al-Damianah).

And the section of the search to the entrance talked about the and his life and age and poetry, and dealt with the first section of religious heritage, The second to picws devoted to literary heritage and proverbs, The third topic was to talk about the his torical heritage, then the conclusion of the research and its results, and a list of sources and references. 
المؤتمر العلمي الاولي الحادي عثر

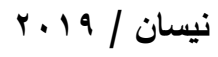

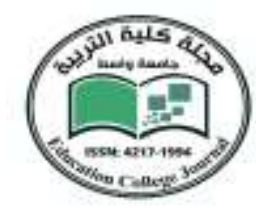

جامعة واسط

مجلــــة كليــــة التربيــــة

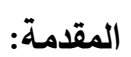

يمثل التراث مخزون الأمة فهو يحافظ على هويتها وانتمائها ،إذ يحوي قيماً ثقافية وفكريـة تكون بمرور الزمن جزءاً من تكوين هذه الأمة ، فالتراث مصدر الهام الثعراء فيؤثر فيهم،ويختلف الثعراء في مقدار هذا التأثر ،ويلجـأ الكثير منهم إلى هذا التراث فينهلون منـه ويوظفونـه في أشعارهم ، والثـاعر ابن الدمينـة واحد من هؤلاء الشعراء وهو شـاعر إسـلامي من شعراء الغزل العذري استطا

توظيف التراث العربي في شعره .فكان عنوان البحث (توظيف التراث في شعر ابن الدمينة). وقسم البحث إلى مدخل تحدثت فيه عن حياة الشاعر وعصره وشعره ، وتتاول المبحث الأول التراث الديني، أما المبحث الثاني فكان خاصاً بالتراث الأدبي والأمثال، أما المبحث الثالث فكان للحديث عن التراث التاريخي، ثم خاتمة البحث ونتائجه ،وقائمة بالمصادر والمراجع • مدخل: الشاعر ابن الدمينة هو عبيد بن عبد الله، والدمينة أمه، وهو من بني عامر من خثعم(') وقيل هو عبد الله بن عبيد الله(؟)، وكنيته أبو السري(r) . . أمسا عصره فقد اختلف فيـه بشكل كبير فقيل هو((شـاعر إسـلامي ))(؛)، وقيل: شـاعر ((متقدم من

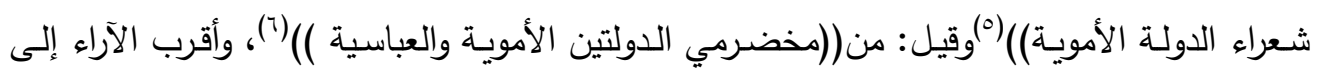
الصحة هو أنـه من مخضرمي الدولتين، وتبنى هذا الرأي محقق ديوانـه، إذ يرى بأن شعره وأخباره وصلاته برجال عصره تدل على ذلك(v) . وأغلب الروايـات تشير إلى مقتله بسبب مـاحم بن عمر السلولي الذي تغزل غزلا فاحشـاً بزوجـة الشـاعر حماء، وأتهم بحبـه لها، كما أتهمت بالخيانـة، فقتله انتقاماً لشرفه، وقتل زوجته وابنـة لهما، وحبس مدة من الزمن وأطلق، فلما رآه مصعب أخو مزاحم في السوق شد عليه، وقتله ثاراً لأخيه (^). ويعد الشـاعر واحداً من شعراء الغزل العذري أمثال كثير عزة وجميل بثينة وشعراء الغزل الآخرين، فشعره كان بمنزلة شعر هؤلاء ،وكان أغلب شعره غزل وتشكي ولوعة وألم من جفاء حبيبته، فكان من شعراء الغزل الذين استطاعوا التعبير عن مشاعرهم الصادقة من خلال أشعارهم ،فنظم أشعاراً جميلة تدل على صدق هذه المشـاعر ونقائها. وشعره يمتاز بالعفـة والطهارة والابتعاد عن الألفاظ البذيئة 
المؤتمر العلمي الاولي الحادي عشر

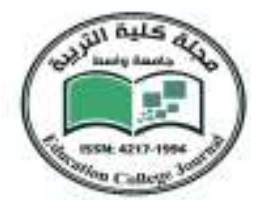

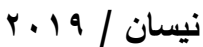

\section{جامعة واسط}

مجلـــة كليــة التربيـة فيسة

والكلمات الفاحشة، وألفاظ شعره من الألفاظ السهلة الواضحة، أما الألفاظ الغامضة فنجدها قليلة في شعره .قال الزبير بن بكار في وصفه:((من أحسن الناس نمطاً ،يجتمع له مع رقة المعاني الفصاحة

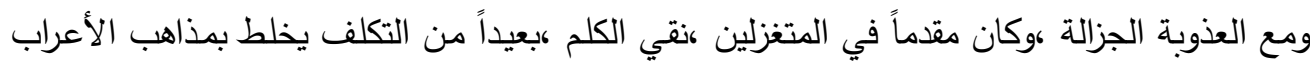

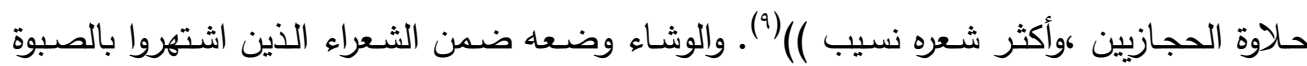
والغزل (·)،وقد اكتوى الثاعر بنار الحب ،وفي حياته أكثر من امرأة تغزل بها، وذكرها في شعره . والثاعر ابن الدمينة وهو من شعراء الغزل العذري تثقف بثقافة واسعة في مختلف المجالات، وهذه الثقافة لها روافد متعددة، وهذه الروافد هي التراث بمختلف مجالاته، والتزراث كل ما هو متوارث مكتوب

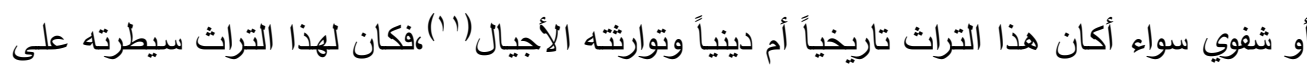
الشاعر ، فكثيراً ما نراه يستلهم في شعره هذا التراث، إذ وظف التراث الديني والأدبي والتاريخي وهذا ما

سنوضحه.

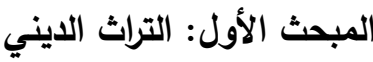

يعد التراث الديني مصدراً من مصادر الإلهام عند الثعراء؛ لأن الدين يرتبط بحياة الإنسان ارتباطاً

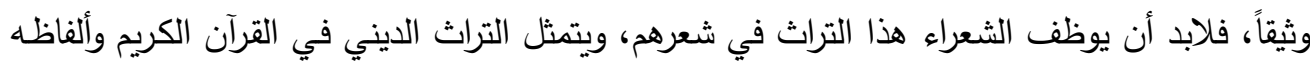
ومعانيه وصوره وتعاليمه، كما يتمثل في العبادات التي أوجبها الله سبحانه وتعالى . فلذلك كان القرآن الكريم يمثل أحد الروافد الثقافية للشاعر، وقد أدرك الثاعر العربي وخاصة الثاعر القديم ما حملته لغة القرآن من بلاغة وروعة أضفت معاني عميقة على الألفاظ العربية، فدخلت هذه الألفاظ والمعاني في الفكر العربي فاستعدها العرب تأثراً بأسلوب القرآن في أشعارهم (r') . ومن توظيف القرآن في شعر ابن الدمينة قوله:

\section{فَيَعْلَمُ ما يَبْدُو لَهله وَيَغِيبُ (T)}

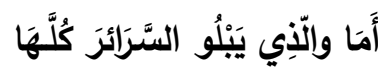

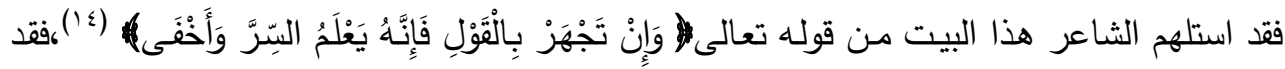
وظف الثاعر النص القرآني بإفادته من معنى الآية الكريمة، ولكنه بدل ألفاظ النص، فلا نجد ألفاظ الآية كما هي، وإنما لجأ إلى التغيير، فكان التوظيف في معنى الآية، كما نجد توظيفه للآية السابقة 
المؤتمر العلمي الدولي الحادي عشر

ن بيسان / 19

جامعة واسط

مجلــــة كليــــة التربيــــة

في قوله:

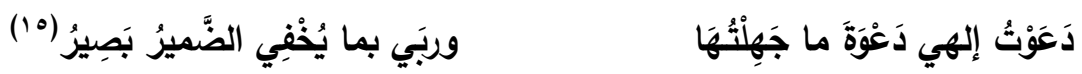

وظف الثـاعر مفهوم الآيـة ذاتها واستلهم المعنى بأن الله سبحانه وتعـالى يعلم مـا يخفي ضمير الإنسان وما يعلن ،فاستطاع الشاعر إيصال فكرة أنه يدعو الله سبحانه وتعالى والله عز وجل وحده

يعلم صدق هذه الدعوة .

ومن استلهام الثاعر من القرآن الكريم قوله :

ولَنْ تَكْسِبا خَيَرْاً مِنَ الحَمْدِ والأَجْر

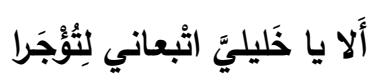

تُصَلِّيكَ أَسْبَابُ الههوى وَهَجَ الجَمْرِ

فقالا: التَّــقِ اللَّة العَلِيَّ فِإنَّما

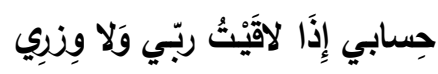

فقلتُ :أطيعاني فليسن عليكما

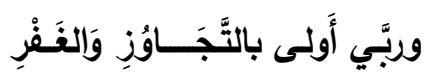

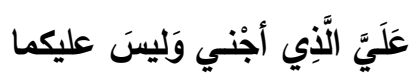

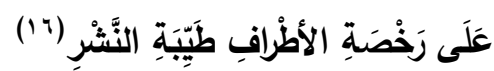

أَتَحْرُفْي يارَبِ إَنْ عُجْتُ عَوْجَةً

فقد وظف الشـاعر عدة آيات في هذا النص، ولكنه أفاد من المعنى وبعض الألفاظ منها قوله

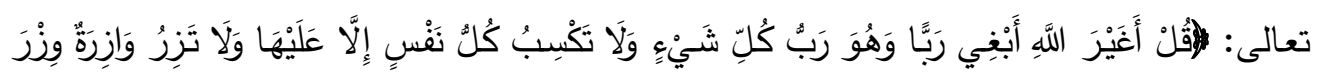

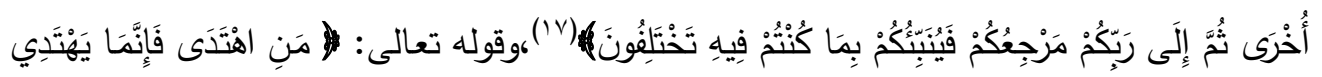

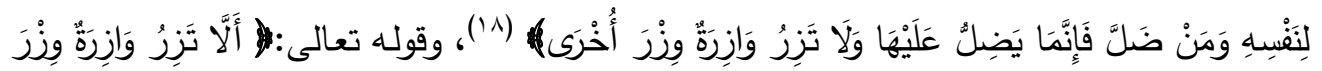

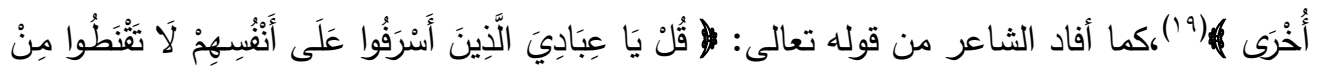

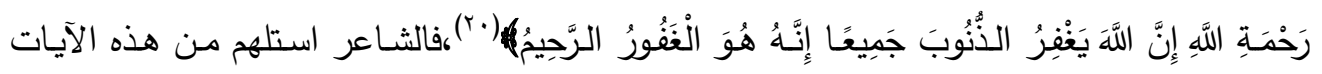
وغيرها في بناء هذا النص، فأفاد معنى أن الإنسـان مسؤول أمسام الله عن ذنوبـه ،وإن الله سيحاسبه عليها ،كما أفاد معنى أن الله سبحانه وتعالى غفور رحيم، فاستطاع الثاعر استعمال ألفاظ الآيات في إيصال المعنى المراد. 
المؤتمر العلمي الدولي الحادي عشر

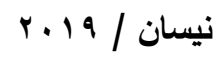

جامعة واسط

مجلــــة كليــــة التربيــــة

أما قوله :

أَم الله إنْ لَمْ يَعْفُ عَنْهَا يُعِيدُهَا

هلِل اللهُ عافٍ عَنْ ذُنوبٍ تَسَلَّفتْ

لِعَضْماءَ بالِي حُلَّةٍ أو جَديدُهَا(r)

وهل يُؤْتِنَنِي اللهُ إنْ قُلَتُ : لَيْتَي

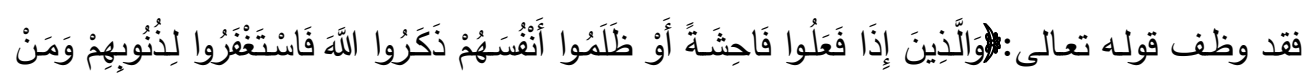

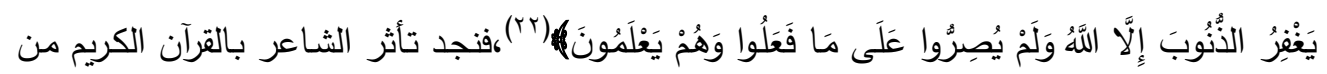
خلال معرفة معاني الآيات، والتأكيد على الذنوب والمغفرة، لأنه من شعراء الغزل العذري، فكثيراً ما يـرتبط هذا الغرض بالحفاظ على تعـاليم الدين، وعدم تجاوزها ،ولكن قوة مشـاعره تجعله يلجأ إلى

الذنوب ويطلب المغفرة .

كما نجد طلب المغفرة من الله سبحانه وتعالى في قوله:

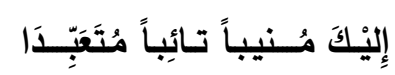

بَي الجَهْلُ مَرْمَيً غَيَرْهُ كانَ أَرْشَدَاب(r)

\section{فيارَبِّ أَدْعولَكَ العَثِيَّةَة مُخْلِصاً}

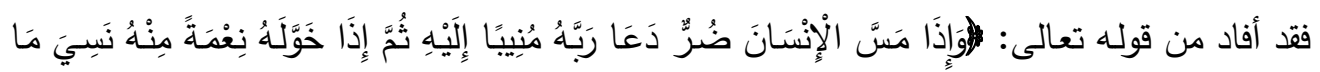

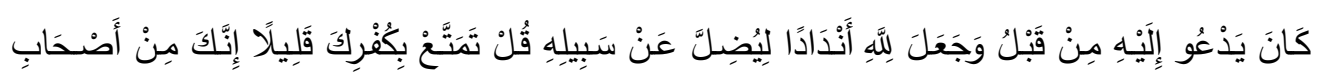

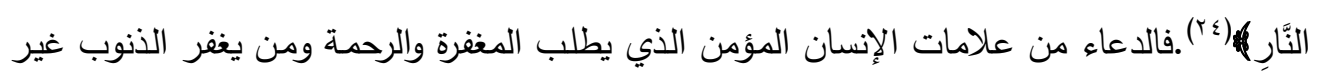
الله سبحانه وتعالى،فالثاعر وظف ألفاظ الآية وبعض معناها في التعبير عن فكرته . كما كانت المغفرة حاضرة في شعره في قوله:

ذَكَرْتُكِكِ لَمْ تُكْتَبْ عَلَيَّ ذُنُوبٌُ (ro) وَلَوْ أَنَّبِي أَسْتَفْفِرُ اللَّة كلَّمَا

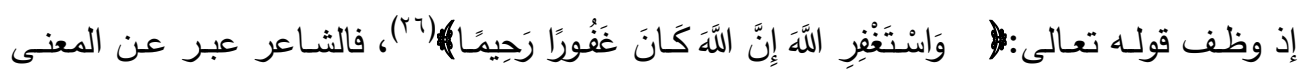
المقصود باستلهامه معنى الآية مع اختلاف الألفاظ ،فالثاعر أراد وصف عمق مشاعره وحبـه وحجم تأثيره عليه فكان يذكر حبيبته بشكل دائم فلو استغفر الثاعر الله سبحانه وتعالى عند ذكرها لم يكتب الب واله عليه ذنباً . لع. 
المؤتمر العلمي الدولي الحادي عشر

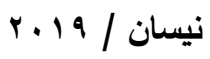

جامعة واسط

مجلــــة كليــــة التربيــــة

وقد استلهم قوله:

هَلْ لِمَا فَاتَ مِنْ الأُنْيَا مَرَدْ (rv)

بَعْدَ دُنْيَا لَيْتَهَا رُدَّتُ لَنَا

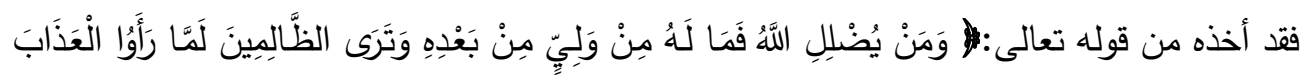

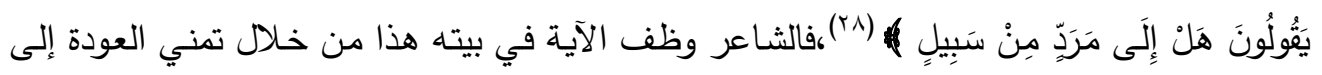
الماضي وذكرياته الجميلة .

كما تأثر بالدين الإسـلامي ،فنجد الثـاعر وظف كثير من العبادات والألفاظ الدينية في شعر الغزل العذري الذي كان تأثره فيه واضحاً.

وَهَلْ أَنَتَ يارَبَّ العُلا مُوجِبٌ نَذْرِي إذ وظف الثاعر النذر في قوله:

أُوَافي بها يومَ الأَبَائَحِح والنَّنْرِ (ra)

\section{صِياماً وَحَجِاً تُمَّ بُدْناً أقودُهُها}

وظف الثاعر مصطلح النذر وهو مصطلح ديني يستعمل لإلزام النفس بشيء غير لازم عليها بأصل الشرع(·r)، والثاعر من شدة حبـه ووجده وتشوقه ليوم اللقاء ألزم نفسه النذر من أجل تحقيق غايته، والاستجابة لدعوتـه، وتحقيق مـراده، فكان نـذه الصـوم والحـج وهـي مـن الفرائض الواجبـة فاسـطاع توظيف هذه العبادات والفرائض في شعره من أجل التعبير عن شدة شوقه. كما نجد في كثير من أبياته توظيفاً لفريضة الحج سواء أكان ذلك من حيث كونها فريضـة أو أماكن الحجاج أو أركان الحج ومن ذلك قوله:

ذُرُاهُنَّ رَمْيَ المُحْرِمِ بالجمَراتِ (باتِ

وَقَيِلا بِنا في ظِلِِهِنَّ وَرَمِيّا

استلهم الشاعر من فريضة الحج أحد مناسكها المهمة وهي رمي الجمرات، فأفاد الشاعر من ذلك في تكوين الصورة التي أرادها بالثكل الذي يتناسب مع غرضد الشعري. ونجد فريضة الصلاة وهي أهم أركان الإسلام في قوله :

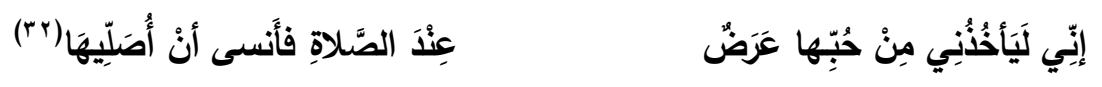


المؤتمر العلمي الاولي الحادي عشر

أراد الشـاعر رسم الصـورة من خـلال توظيف فريضـة الصـلاة التي عدها الله سبحانه وتعـالى عمود

الإسلام، وجاء في الحديث الثريف ((والصّلاة عمود الدين تكمل بها الأعمال وهي أول ما يسأل عنها

المسلم، فإن صلحت صلح سائر عمله، وإن فسدت فسد سائر عمله)(ب"فالشاعر أراد التعبير عن شدة حبه وعشقه وكثره تفكيره بهذا الحب حتى ملك عقله وشغله عما سواه، فهذا الحب قد شغله عن

الصلاة فنسي كيف يصليها.

$$
\text { وقولله : }
$$

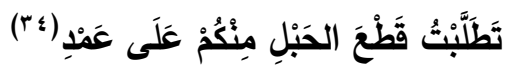

فَوَللهِهِ رَبِ الَبَيتِ لا تَجْدِينَبِي

وكان توظيف التراث الديني في هذا البيت بصيغة القسم، والقسم يدل على أهمية المقسم به مما يدل على أهميـة الفكرة التي أراد الثـاعر من حبيبته تصديقه فيها، وعدم الثك في نوايـاه لذلك استعمل أسلوب القسم، وهو قد استلهمه من القرآن الكريم . ونجد القسم وهو دلالة على الإيمان والصدق في قوله :

\section{كَلَّا وَرَبِّ مُحَمَّدٍ وبِــلالِ}

كَلّا وَرَبِّ الطُّورِ والأَنْفَالِ(r)
أ أخُونُ مِنْ بَعْدِ المَودَّةِِ وَالَهَوىى

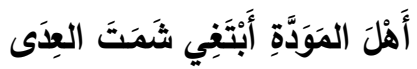

عمد الثاعر إلى استدعاء الشخصيات الدينية في القسم فهو يقسم برب عحم وبـلال هذه الثخصيات تدل على مكانتها وأهميتها في التاريخ الإسـلامي ودورها في نشر الإسـلام والحفاظ عليه، وبـلال هو

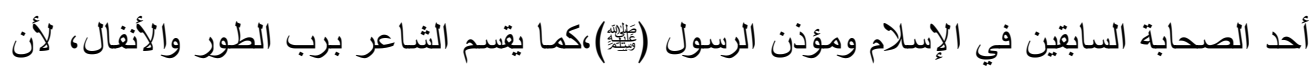
الطور آية من آيات الله الدالة على قدرته التي لا تمنع عذابه ،والأنفال هي من سور القرآن الكريخ التي تتعلق بغزوة بدر،فهذه الشخصيات والسور التي أقسم الشاعر بربها تدل على أهميتها ومكانتها ،فللك ولثقافة الثاعر الدينية استطاع توظيفها في رسم الصورة المعبرة من خلال قسمه بنفي خيانته 
المؤتمر العلمي الاولي الحادي عثر

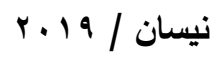

جامعة واسط

مجلــــة كليــــة التربيـــة وامسطة

ونجد قول الشاعر :

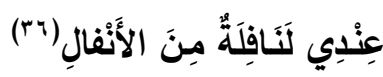

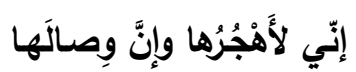

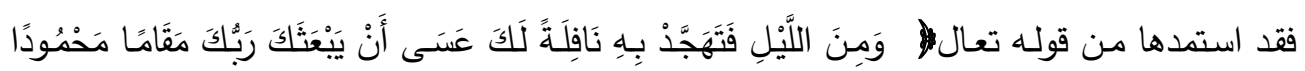

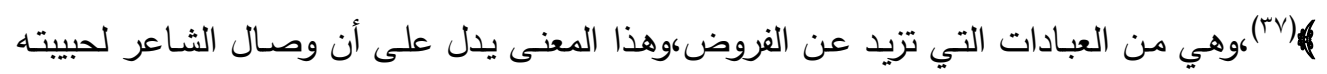
يزيد من حبه لها كما تكون النافلة زيادة في العبادة وغير واجبة ولكنها تدل على زيادة الإيمان. ونجد ألفاظ الدين ماثلة في قوله:

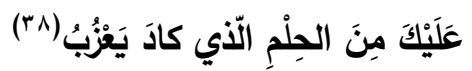

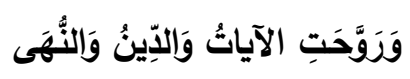

وظف الثاعر في هذا البيت الألفاظ الآيات والدين والنهى وكلها ألفاظاً دينية في رسم الصورة المعبرة

وهذا يدل على سعة ثقافته الدينية وقدرته على استعمال الألفاظ المناسبة في مواضعها . المبحث الثاني :التراث الأدبي يعد التراث الأدبي أحد روافد الثقافة العربية، فلابد للشعراء أن يستلهموا منه ويوظفوه في أشعارهم،

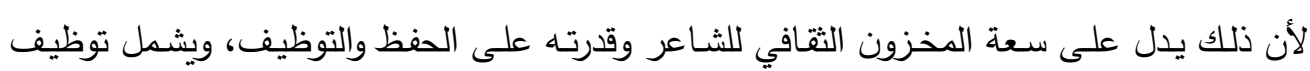
التراث الأدبي استدعاء نصوص الثعراء أو شطراً منها أو استلهام معاني الشعراء وألفاظهم أو صورهم

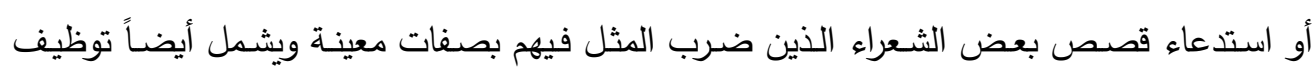
الأمثال وغيره من مجالات الأدب. وقد جاء توظيف ابن الدمينة في قوله:

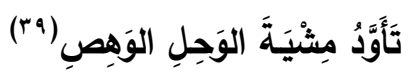

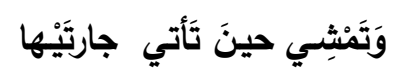

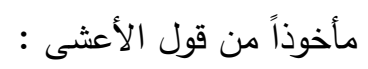

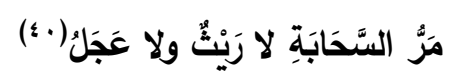

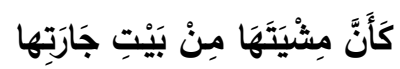
وابن الدمينة في هذا التوظيف قد إفـادة من الثطر الأول من بيت الأعثى بألفاظه ومعنـاه، أمـا

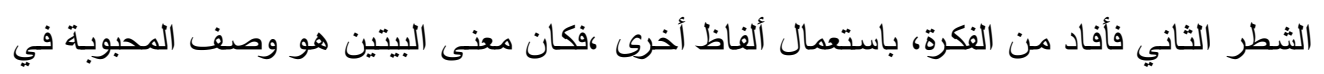
مشيتها . 
المؤتمر العلمي الدولي الحادي عشر

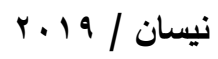

جامعة واسط

مجلــــة كليــــة التربيــــة

ومن استلهامه للتراث الأدبي قوله :

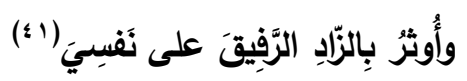

أَبِيتُ خَمِيصَ البَطْنِ غَرْنَانَانَ جائِعاً

فقد أفاد من قول أبي خراش الهذلي

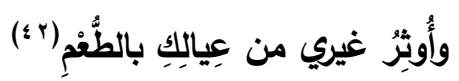

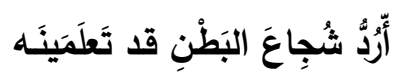

وظف الثاعر الكثير من ألفاظ البيت ومعناه للالالة على فكرة وهي الكرم ولكنه في بيته يكرم الرفيق أما بيت أبي خراش كان إيثار الأبناء وإطعامهم ،هن ذلك ندرك عمق الصورة التي قصد إليها ابن لئن

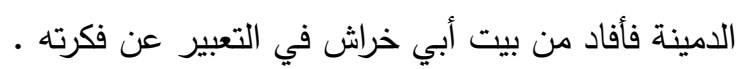
وتأتي قدرة الثاعر على التوظيف والتحوير في قوله:

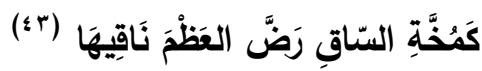

عَجْزَاءُ مُدْبِرَةً هَيْفَاءُ مُعْبَلَةً

فقد أخذه من قول كعب بن زهير

لا يُشتَكى قِصَرْ مِنْهَا، وَلا طُولُ (؛ ؛)

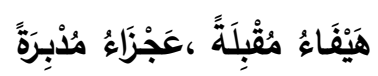

فالثاعر استلهم بيت كعب، فوظف الثطر الأول بألفاظه ومعناه، وكان التحوير في الثطر الثاني،

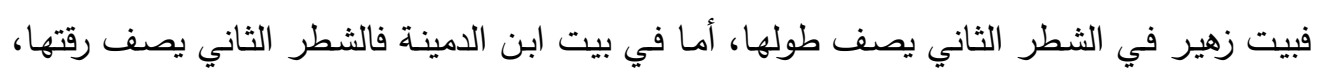
وهنا تظهر قدرة الثاعر على التحوير للمعنى والتصرف فيه وأخذ ما يناسبه ،وحسن توظيفه بما يتلائم

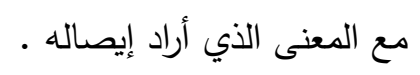
ومن توظيفه للتراث الأدبي قوله:

نِ باتتْ خمائلْهُ تُمْطَرُ (0)

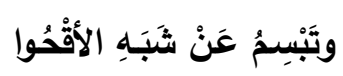

إذ وظف بيت مالك بن الريب:

كما شيف الأقَّاحي بالقطار († ؛) وتبسَحَ عن نَقِّي اللون عَذْبِ 
المؤتمر العلمي الاولي الحادي عثر

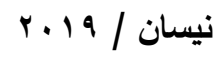

جامعة واسط

مجلــــة كليــــة التربيــــة

فالصـورة ذاتها وكـان الاختلاف في مواضـع الألفاظ ففي البيتين وصف لجمـال الفم فابن الدمينـة استطاع توظيف البيت بما يخدم نصه وهذا دليل على ثقافة الثاعر ووعيه وإفادته من أغلب الثعراء في عصره أو العصور السابقة. كما نجد التوظيف حاضراً في بيت ابن الدمينة:

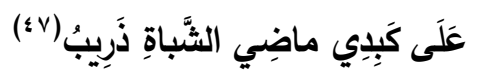

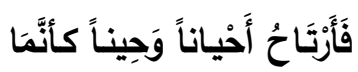
استلهم بيت ذي الرمة :

عَلَى كَبِدِي بَلْ لَوْعَةُ الْبَيْنِ أَوْجَعُ(^؛) كَأَنَّ سِنَانَاً فَارِِِيِاً أَصَابَتِي أفاد الشاعر من توظيف التراث في رسم الصورة التي أراد التعبير عنها مع اختلاف المعنى وعمق الصورة فالشاعر ابن الدمينة وصف كبده بأنها طعنت برمح حاد من شدة الفراق وما تجيش بـه نفسـ من مشاعر الألم، أما بيت ذي الرمة فهو أيضا أصابه الرمح في كبده ولكنه يرى أن الم الحب ولوعته بله أوجع من الم الرمح وإصابته لكبده،فالتوظيف واضح في هذا البيت . وقال ابن الدمينة :

ومُنْيْةُ نَفْسِ عِنْدَ مَنْ لا يَنالهُها (9 ؛) خَليليَّ ما يُغْنى التَّاني مِنَ النَّوَى فقد استلهمه الثاعر من قول جرير :

سَواءً علينا نأيُها واقترابها(·)

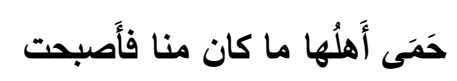
نلاحظ تشابه البيتين في المعنى فكلاهما عن أن القرب لا يبعدهم عن الفراق والنوى ،فالثاعر عمد إلى توظيف الصورة في بيت جرير وجعلها مناسبة في بيته الشعري . ووظف الثاعر بيتا آخر لجرير في قوله :

كَذُوباً وَأَهْوَالُْ المَتَامِ كَذُوبُ ( ) وَبالحَقْلِ مِنْ صَنْعَاءَ كانَ مَطافُهَا إذ استعمل بيت جرير :

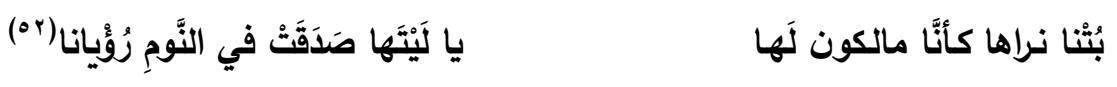


المؤتمر العلمي الاولي الحادي عثر

ن بيسان / 19

جامعة واسط

مجلــــة كليــــة التربيــــة

تظهر في بيت ابن الدمينة قدرته على الإفادة من المخزون الثقافي للثاعر فقد وظف فكرة أن الطيف

محض خيال ووهم وليس حقيقة فهذه الفكرة التي يقوم عليها بيته وبيت جرير مع اختلاف الألفاظ .

ويقول ابن الدمينة :

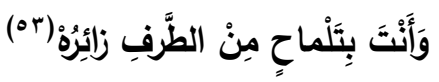

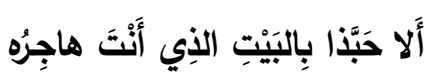

مأخوذ من بيت السمهري العكلي:

فلا البيتُ منسيُّ ولا أنا زائرُهُ (؛ ه)

ألا أَيها البيثُ الذي أَنا هاجَرُه

وظف الثـاعر بيت السمهري بمعناه وفق ما يلائم مقصده فالبيت الذي هجره الشاعر يراه من بعيد أما في بيت السمهري فلا يراه وذلك لأنه بعيداً عنه في السجن . وقد يعمد الثاعر إلى استدعاء الشخصيات الأدبية وتوظيفها في سياق بيته الشعري ومن ذلك قوله:

وَعَمْرِو بن عَجْلانَ الأي قَتَََتْ هِنْدُ (00)

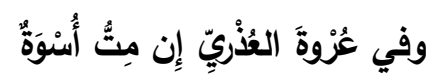

فالثاعر استدعى شخصيات أدبية في هذا البيت من أجل توظيف قصص عشقهم ليعبر عن حبه ولوعته وتضحيته ،فقد استدعى شخصية عروة بن حذام وقد ضُرب المثل بعشقه ((لأنه كان أطولهم

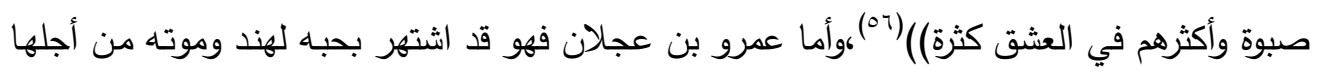
فالشاعر عندما يذكر هؤلاء الشعراء إنما يشير إلى قصص العشق والحب العذري حتى أصبحت عنده نموذجاً يحتذى أو يضرب به المثل فهو أراد أن يربط حبه بقصص الحب العذري وقد أجاد في ذلك بشكل واضح .وتعد الأمثال من مصادر التراث الأدبي المهمة وتدل على ثقافة الثـاعر وسعة حفظه وقدرته على توظيفها بالشكل المناسب، إذ قال ابن الدمينة :

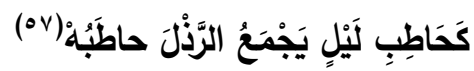

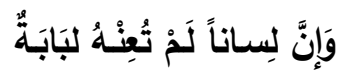

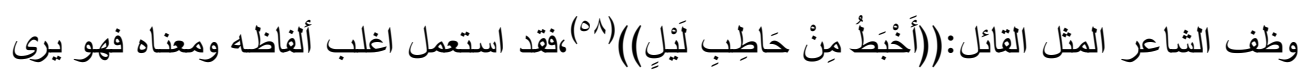
أن اللسان إذا لم يستعمل مع العقل فهو يشبهه بحاطب الليل الذي يجمع ما يحتاج إليهه وما لا يحتاج إليه ،فاستطاع توظيف المثل في موضعه المناسب . 
المؤتمر العلمي الاولي الحادي عثر

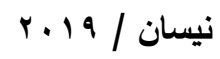

جامعة واسط

مجلــــة كليـــة التربيـــة

وقال ابن الدمينة:

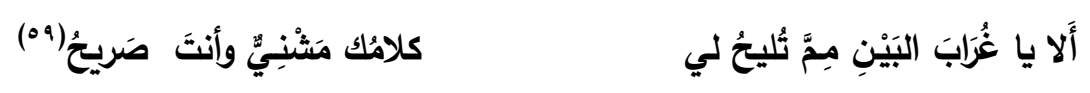

في هـا البيـت تثـائم الثـاعر مـن الغراب ولـذلك وظـف المثل القائلل)((أثـأم مِنْ غـرابِ

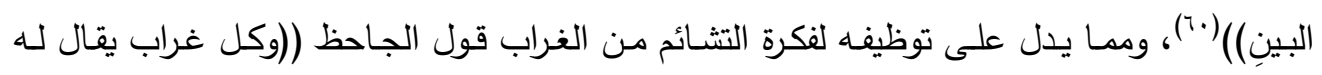

:غراب البين ،إذا أرادوا به الثؤم ...وإنما قيل لكل غراب (غراب البين )لسقوطه في مواضع منازلهم

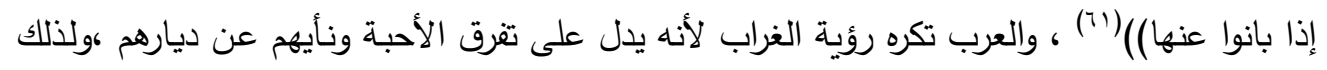

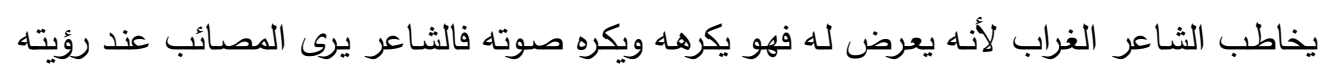

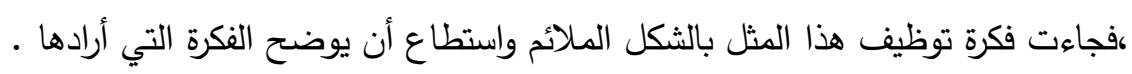
قال الثاعر :

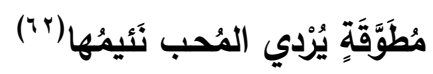

يَهيجُج عليَّ صَوْتُ حَمَامَةٍ

استلهم الثاعر صوت الحمامة في التعبير عن الحزن والألم الذي يشعر به إذ وظف المثل

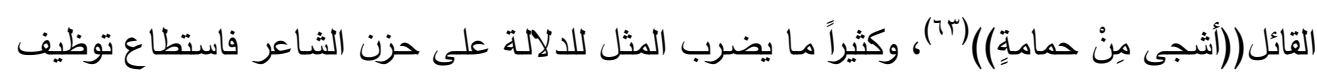
المثل ورسم الصورة المعبرة الجميلة .

المبحث الثالث :التراث التاريخي

يعد التراث التاريخي من مصادر ثُقافة الشاعر مما يسهم في تكوين ألفاظه ومعانيه وصوره ،ويشمل رافداً متعددة منها أيام العرب والثخصيات التاريخية والأساطير والمعتقدات. وكانت المعتقدات والعادات تأخذ جزءاً من مخيلة الفكر الإنساني وتؤثر عليه فهي منفذاً لدراسة عقلية

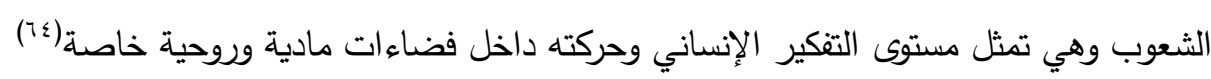

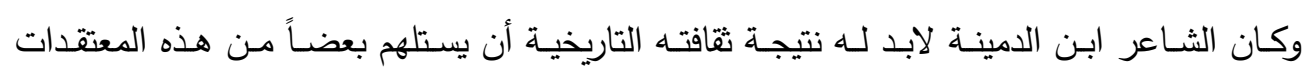

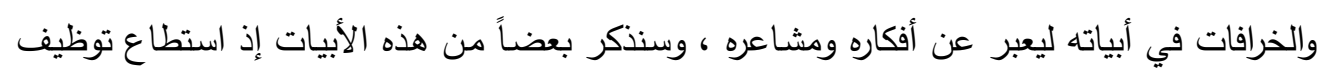
التراث التاريخي بمختلف أنواعه في هذه الأبيات . 
المؤتمر العلمي الدولي الحادي عثر

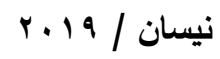

جامعة واسط

مجلــــة كليــــة التربيــــة

قال ابن الدمينة:

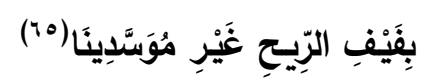

وَغَادَرْنا فَوارَِِنهُ وَرِعْلاً

وظف الثاعر أحد أيام العرب وهو يوم فيف الريح وهو من الأيام التاريخية المهمة وهو بين عامر بن صعصعة والحارث بن كعب وكانت بنو عامر تطلب بني الحارث بن كعب بأوتار كثيرة ، وكان الثرف فيها لبني عامر (די)، ،الثـاعر هنا استعمل هذا اليوم للفخر بقبيلته فقد تركوا فوارس الأعداء قتلى في ساحة المعركة ،فأفاد الثـاعر من ثقافته في مجال فخره بقبيلته.إما في مجال المعتقدات والخرافات فقد أفاد من هذا الجانب من ثقافته في قوله:

عَوَابِسَ كَالسَّعَالِى قَْْ وَجِينَا (rv) فَقُدْنْا الخَيْلَ تَعْتُرُ فِي قَّناها فالثـاعر وظف مفردة السعالي ،فالسعلاة فهي نوع من الثياطين وهي ((حيوان يتراءى للناس بالنهار ،ويتغول بالليل وأكثر مـا يوجد بالغيـاض، وإذا انفردت السعلاة بإنسـان وأمسكته ، صسارت ترقصه وتلعب به)()(7^)،والسعلاة هي ذكر الغول إذ يقول ابن منظور :((والغول ساحرة الجن قال أبو

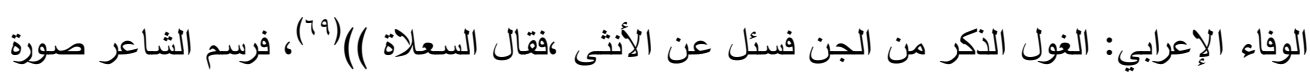
لخيل المعركة وهي عابسة وشبهها بالسعلاة دلالة على التجهم والخوف عند رؤيتها فاستطاع توظيف هذه الخرافة في رسم الصورة الشعرية التي أرادها. واستلهم الشاعر الخرافة ذاتها وهي السعلاة في قوله :

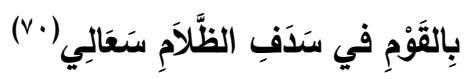
صَحْبِي بِذِكْرِكِ والْمَطِي كأنَّهُ فالثاعر اعتمد على هذه الخرافة ووظفها في رسم هذه الصورة فأراد رسم مشهد الرحيل في الظلام فهو يشبهه بالسعالي وما تثيره صورة السعلاة في نفس الإنسان من الخوف والتوتر والقلق . قال ابن الدمينة : ق

مِنَ الإنْسِ مُزْوَرٌ الجَنَاحِ كَتُوُمُ أَخا الجِنِ بلِّفْهَا السَّلاَمَ فِإنتِي

خَليلٌ صفاءَ الوُلِّ كيفَ نُدِيمُ (v) أخا الجِنِ لَا نَذْري إذا لم يُدِمْ لنا 
المؤتمر العلمي الاولي الحادي عثر

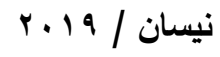

جامعة واسط

مجلــــة كليـــة التربيـــة

آمن العرب بالجن وتأثروا بهذا المعتقد و ((الجِنَّ خلاف الإنس سمّوا بذلك لاستتارهم عن الناس وهم مخلوقات خفية)() (Vץ) ،وقد اعتقد العرب أنها تخالطهم في كل مكان لذلك استعاذوا بها واحتموا ولجئوا

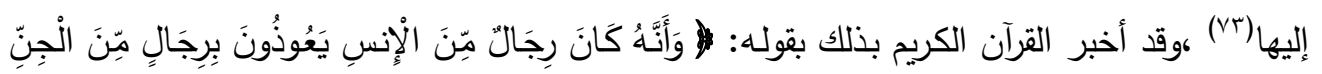

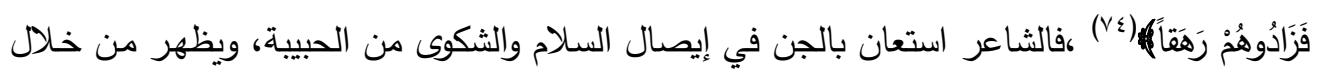
هذا التوظيف للجن في هذا البيت قدرة الثاعر على رسم حجم المعاناة التي يحس بها نتيجة هذا الحب ولوعته . قال ابن الدمينة:

كَأَن بِها لَمَّاتِ جِنِ تُطِيُرها (vo)

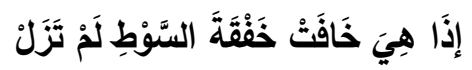
وظف الثاعر الجن في هذا البيت في وصف الناقة وخوفها من ضربة السوط واضطرابها كأنه قد مسها الجن وهذه الخرافة قد آمن بها العرب واستعملوها في أشعارهم، فيبدو أن الثاعر استطاع رسم فئ الصورة بالاستعانة بثقافته واطلاعه على المعتقدات والعادات . قال الثاعر :

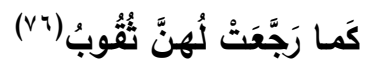

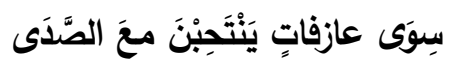
استلهم الثـاعر مصطلح عازفات وهو قد استعمل في الأشعار القديمة وقد وضحه ابن الإعرابي

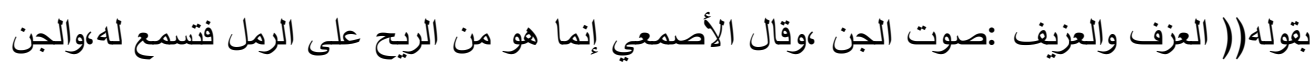

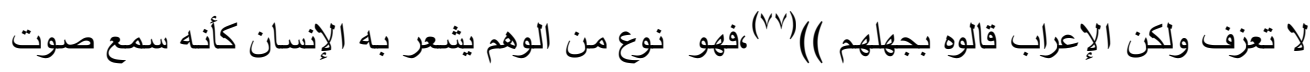

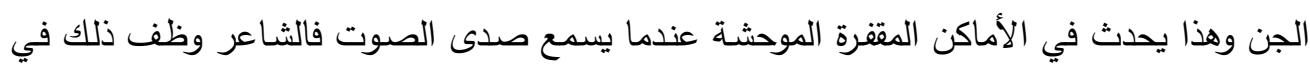
رسم صورته التي يصف بها منازل حبيبته بعد رحيلها. والهامة والصدى من الخرافات التي وظفها الثاعر تأثراً بالمعتقدات الجاهلية ،وقد كان العرب في العصر الجاهلي يزعمون أنه إذا قتل رجل منهم ولم يؤخذ بثأره خرجت هامة المقتول وهو طائر يسمى الصدى ينادي في الليل اسقوني... اسقوني

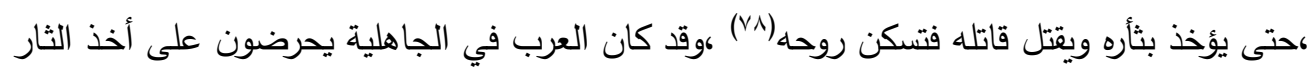

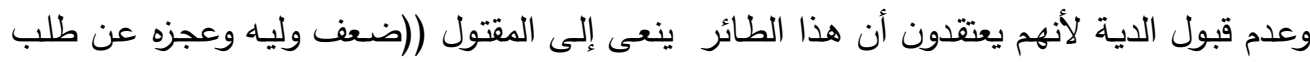
طائلته ،وهذا كانت تقوله الجاهلية)( (va) . 
المؤتمر العلمي الاولي الحادي عثر

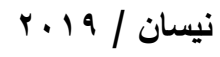

جامعة واسط

مجلــــة كليــــة التربيــــة

فالثاعر ابن الامينة وظف هذه الخرافة وفق الغرض الذي أراد التعبير عنه وهو الغزل إذ قال:

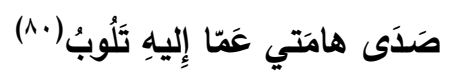

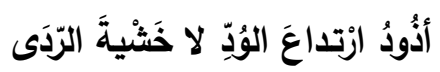

وظف الثـاعر الصدى والهامـة في هذا البيت فهو لا يتتازل عن حبـه خشية الموت والهلاك ولكن يخشى صدى هامته التي تظهر بعد موته فتطالبه بهذا الحب والود وتلومـه عن التنازل عنه أو عدم الحفاظ عليه ، فوظف هذه الخرافة في سياق الغزل وليس طلبا للثار . ومن توظيف الثاعر لهذه الخرافة قوله:

إذاذا ماتَ مَوْتاها تَعَارَفَ هامُهَاِا(1)

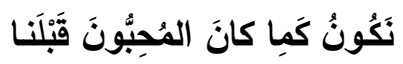

إذ استلهم من ثقافته هذه الخرافة في التعبير عن حبـه وشدة تعلقه بحبييته حتى بعد الموت ويستلهم قصص المحبين السابقين ويكونوا مثالا يحتذي الثـاعر بهم فيرى التقاء هامـة الثـاعر بعد موته مـع هامة حبيبته وهذا يدل على نقاء حبه الأبدي وصدق مشاعره .

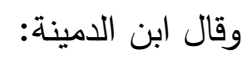

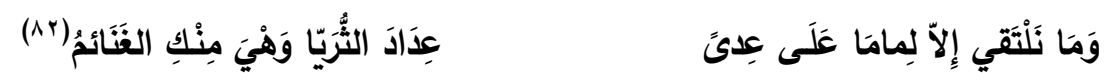

كان العرب يسمون الثريا باسمها لأنهم كانوا يتبركون بها وبشروقها ويزعمون أن المطر الذي يحدث في أثناء شروقها وغروبها يجلب الثروة، وكانت الثريا هي المنزل الثالث من منازل القدر ،وكان بعض من العرب يعبدون الكواكب ويستدلون بها في السفر ولا يقيمون في موضع أو يسافرون إلا إذا استدلوا

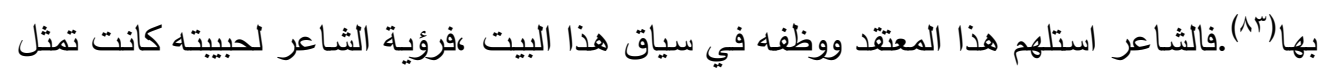
الغنيمة عنده كما تمثل رؤية الثريا الخير والعطاء. 

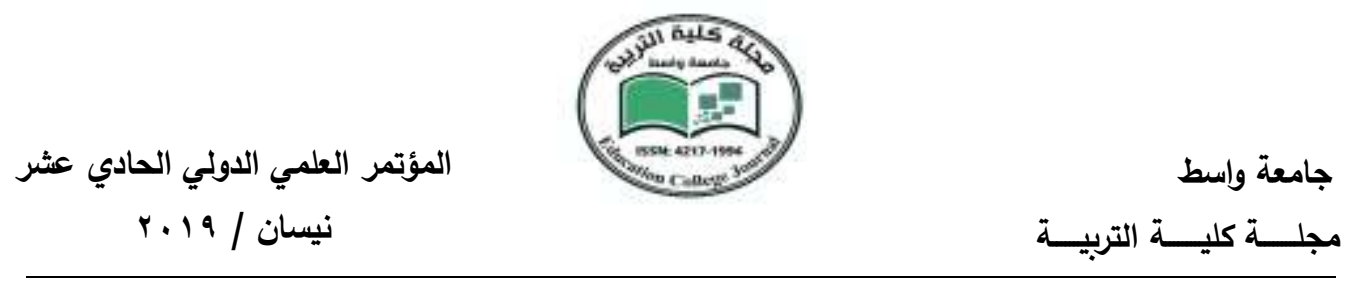

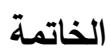

وفيما يأتي عرض لأهم النتائج التي توصل إليها البحث :

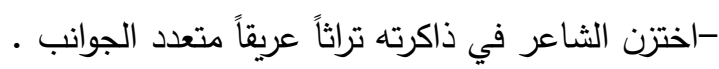

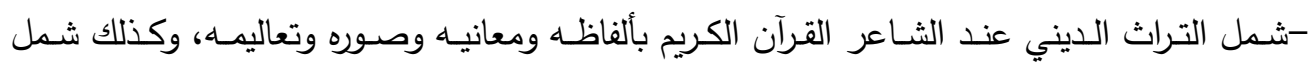

العبادات وأركان الإسلام التي وظفها الثاعر بالثكل المناسب، وتوظيف شخصيات وأماكن دينية.

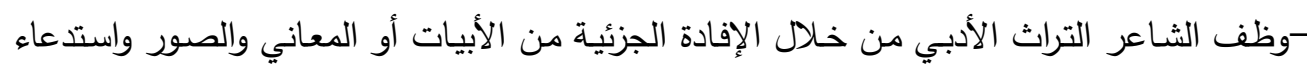

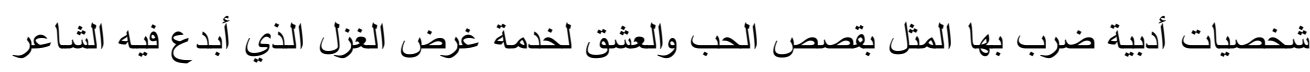
بشكل واضح. -كان استلهام التراث التاريخي من خـلال الاطـلاع على تاريخ العرب فأفاد من أيـام العرب ومن الخرافات والمعتقدات والعادات.

-امتلك الثاعر قدرة كبيرة على تحوير الألفاظ والمعاني والصور ، والتصرف فيها، وجعلها مختلفة،

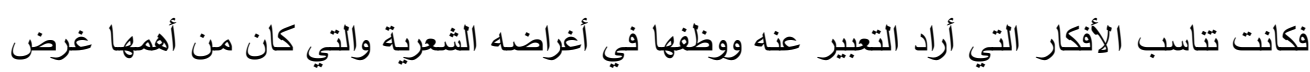

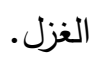

المصادر والمراجع

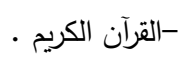

- أثر القرآن في الأدب العربي في القرن الأول الهجري،ابتسام مرهون الصفار ،مطبعة اليرموك،بغذاد، ع 9 ام.

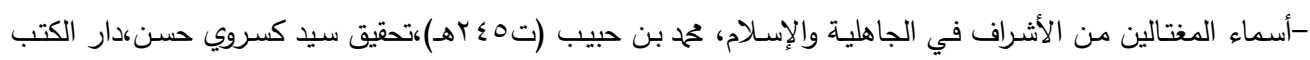

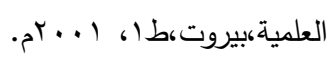

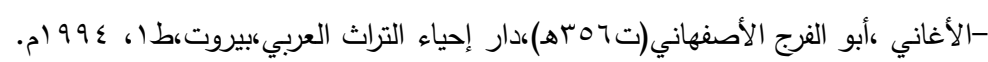

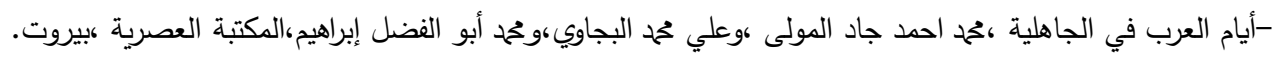

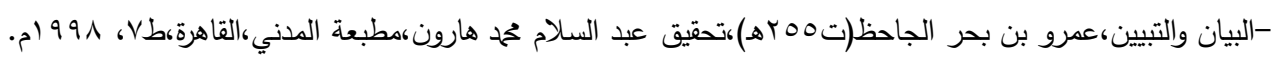

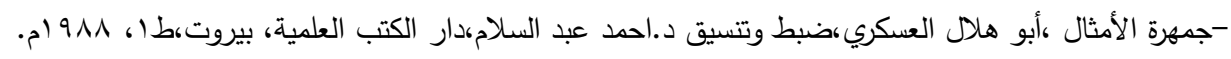
- الحياة العربية من الشعر الجاهلي ،د. أحدد حمح الحوفي ،دار القلم ، بيروت، الدمدت).

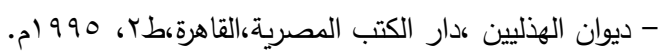


المؤتمر العلمي الدولي الحادي عثر

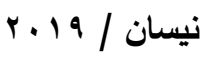

جامعة واسط

The coneng 3 مجلــــة كليــــة التربيــــة

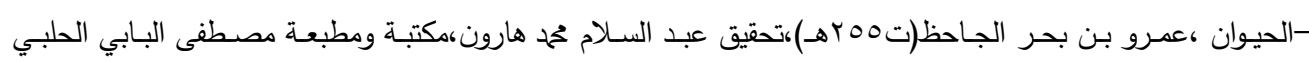

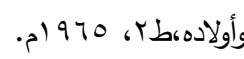

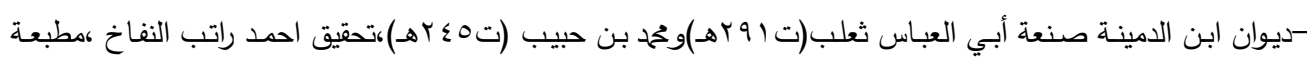
المدني،مصر ،د.ط،د.ت.

-ديوان الأعشى الكبير ميمون بن قيس ،شرح وتعليق د.محم حسين،المطبعة النموذجية، مصر ،د.ط، د.ت.

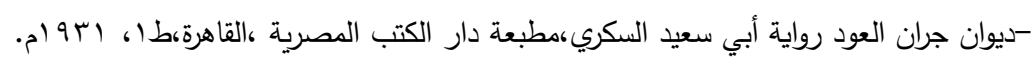

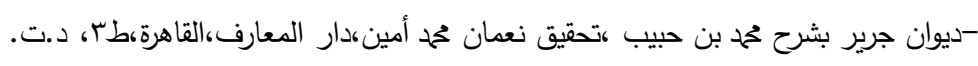

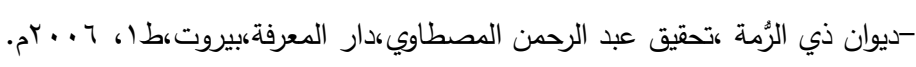
-ديوان كعب بن زهير،تحقيق علي فاعور ،دار الكتب العمية،بيروت، و99 ام. 9 ام.

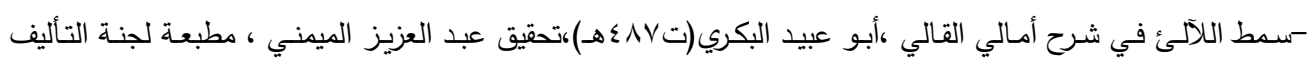
والترجمة والنشر ،د.ط، بـ 9 ام.

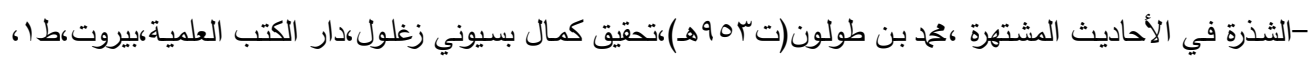
.01994 -الثعر وأيام العرب في العصر الجاهلي،د.عفيف عبد الرحمن ،دار الأندلس،بيروت ،طا ، ع 9 ام. -الثعر والثعراء ،ابن قتيبة(ت وVYVI)،تحقيق وشرح أحمد محمد شاكر ،دار المعارف القاهرة،ط اكد.ت.

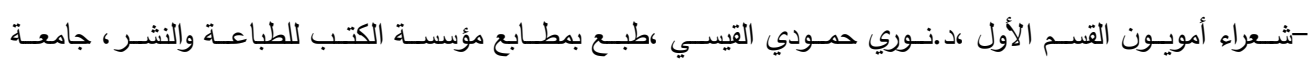

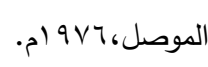

- العناصر التراثية في الرواية العربية في مصر،مراد عبد الرحمن ،دار المعارف، القاهرة، طا، 919 ام.

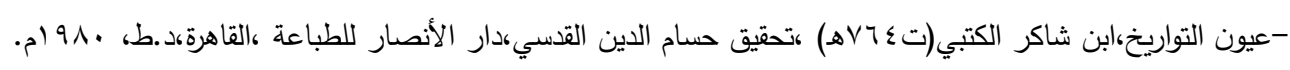

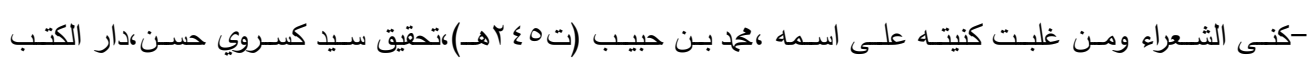

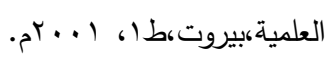

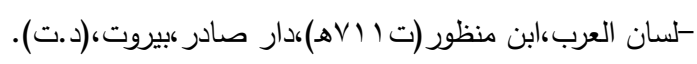

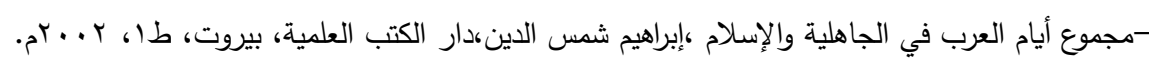
-المستطرف في كل فن مستظرف، شهاب الدين بن أحمد أبي الفتح الابشيهي (ته . ـهـ)، شرح مفيد محمد قميحه ،دار

$$
\text { الكتب العلمية،بيروت،طب، ؟ +. rم. }
$$

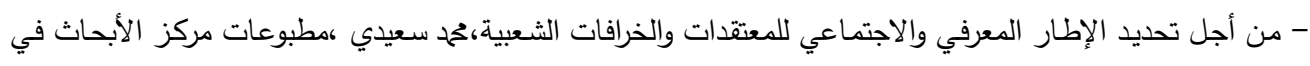

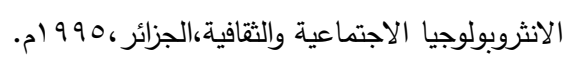

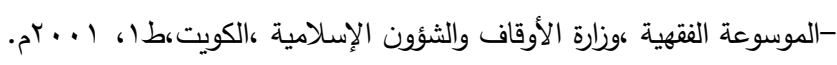




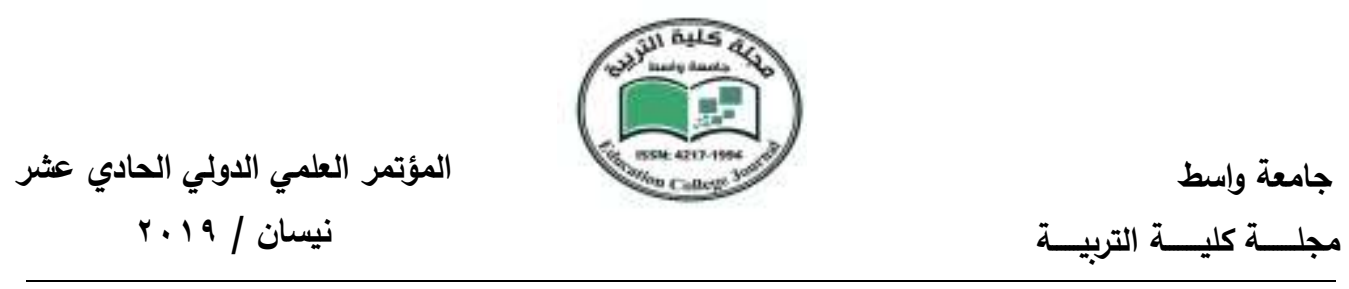

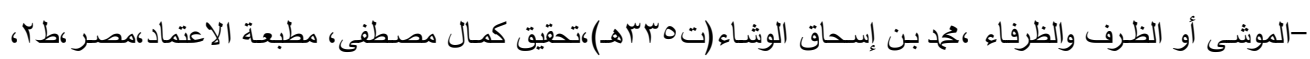
.

الخهو امش

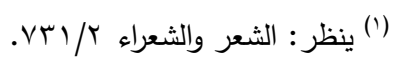

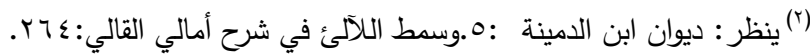

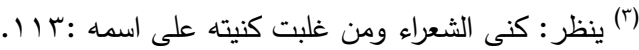

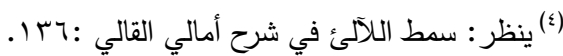

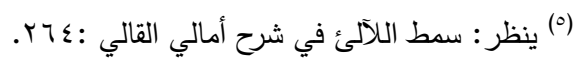

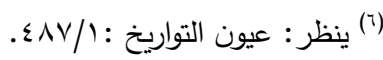

rV: ينظر : ديوان ابن الدمينة : (v)

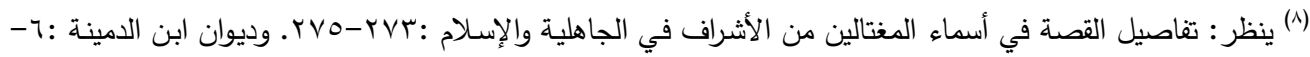

$$
\begin{aligned}
& \text { V }
\end{aligned}
$$

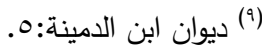

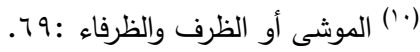

(")

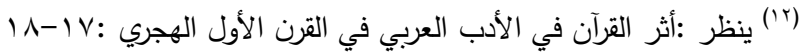

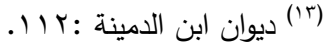

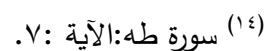

(10)

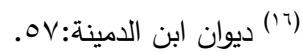

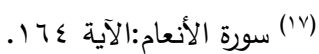

(1) سورة الإسراء :الآية 10.

(9) سورة النجم :الآية میا.

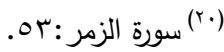

(r) ديوان ابن الدمينة:

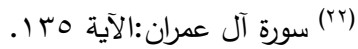

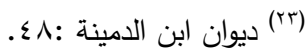

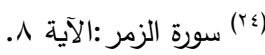

(ro) ديوان ابن الدمينة:11) 11 (1)

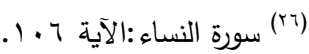

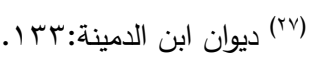



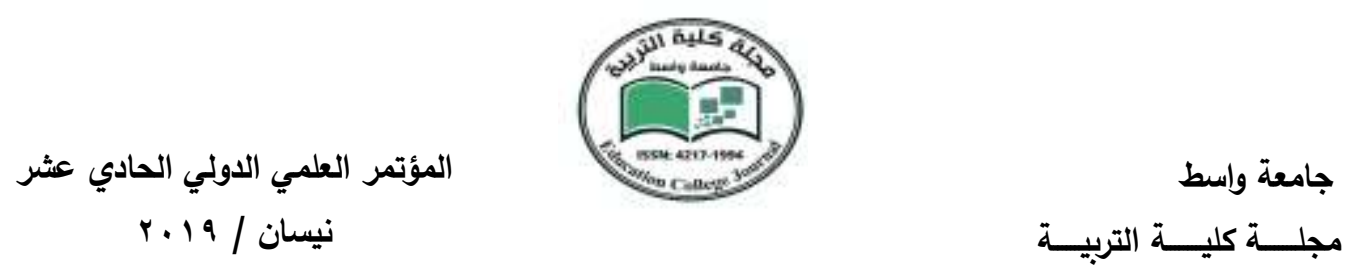

$$
\begin{aligned}
& \text { سورة الثورى:الآية:؟ ؟. }
\end{aligned}
$$

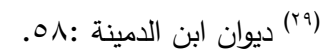

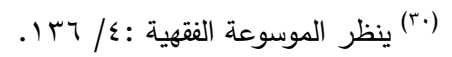

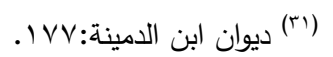

$$
\begin{aligned}
& \text { (ابن }
\end{aligned}
$$

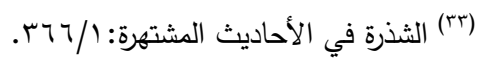

$$
\begin{aligned}
& \text { (بء) } \\
& \text { (ro) }
\end{aligned}
$$

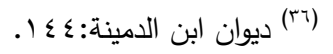

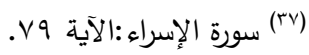

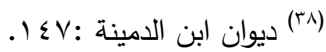

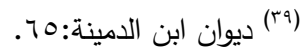

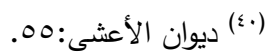

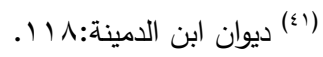

$$
\begin{aligned}
& \text { (ז) }
\end{aligned}
$$

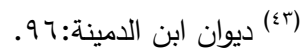

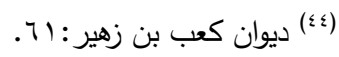

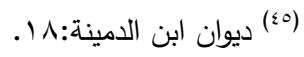

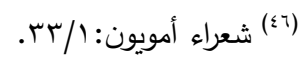

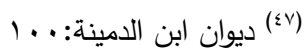

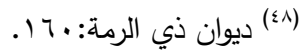

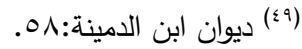

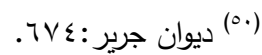

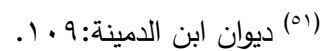

$$
\begin{aligned}
& \text { (Or) }
\end{aligned}
$$

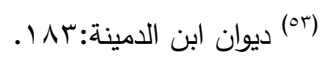

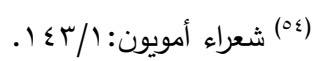

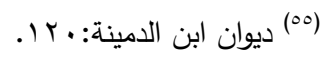

$$
\begin{aligned}
& \text { (07) }
\end{aligned}
$$

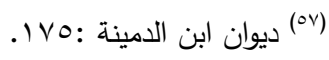

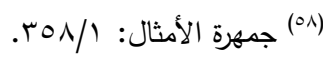



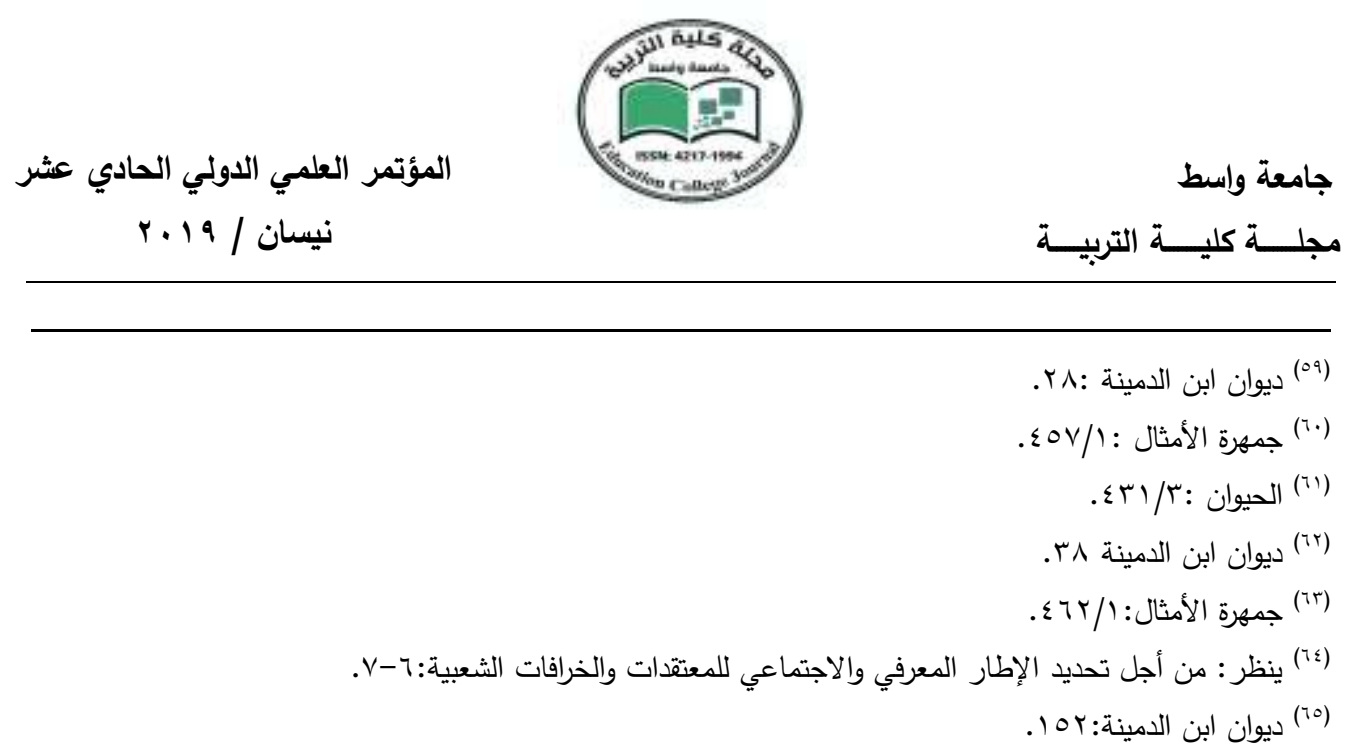

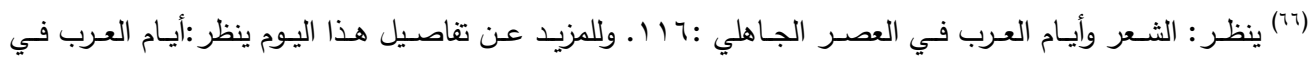

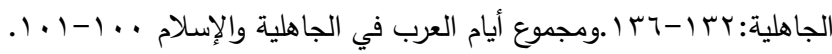
. ديوان ابن الدمينة:(T)

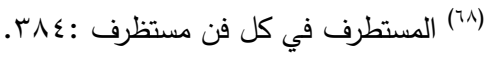

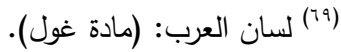

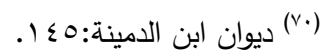

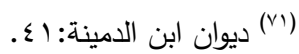
(ماد) (Vr) ينظر :الحياة العربية من الثعر الجاهلي :(VT)

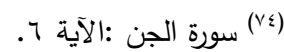

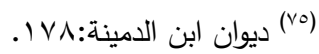

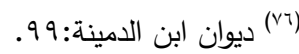

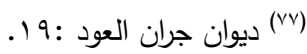

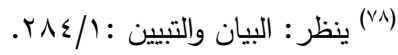

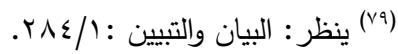

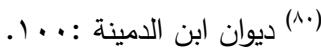

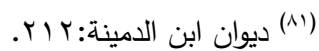

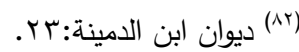
ينظر :الحياة العربية من الثعر الجاهلي:بr) 